\title{
Polycythemia Vera, Polycythemic Phase
}

National Cancer Institute

\section{Source}

National Cancer Institute. Polycythemia Vera, Polycythemic Phase. NCI Thesaurus. Code C41232.

Polycythemia vera characterized by the proliferation of the erythroid, granulocytic, and megakaryocytic lineages. The peripheral blood shows excess of red blood cells, neutrophilia, and thrombocytosis. The bone marrow is hypercellular for the patient's age. 